\title{
Differences in Male Climacteric Symptoms and Lifestyle Depending on the Duration of Working among Rotating Night Shift Workers
}

\author{
Sachiko Kubo ${ }^{1,2 *}$, Toshiyuki Yasui ${ }^{3}$, Reiko Okahisa4, ${ }^{4}$ Yukie Matsuura ${ }^{3}$, Masahito Tomotake ${ }^{5}$ \\ ${ }^{1}$ Graduate School of Health Sciences, Tokushima University, Tokushima, Japan \\ ${ }^{2}$ Faculty of Nursing, Shikoku University, Tokushima, Japan \\ ${ }^{3}$ Department of Reproductive and Menopausal Medicine, Tokushima University Graduate School, Tokushima, Japan \\ ${ }^{4}$ Department of Community Health Nursing, Tokushima University Graduate School, Tokushima, Japan \\ ${ }^{5}$ Department of Mental Health, Tokushima University Graduate School, Tokushima, Japan \\ Email: *sachiko-kubo@shikoku-u.ac.jp
}

How to cite this paper: Kubo, S., Yasui, T., Okahisa, R., Matsuura, Y. and Tomotake, M. (2020) Differences in Male Climacteric Symptoms and Lifestyle Depending on the Duration of Working among Rotating Night Shift Workers. Health, 12, 1598-1609. https://doi.org/10.4236/health.2020.1212116

Received: November 23, 2020

Accepted: December 21, 2020

Published: December 24, 2020

Copyright (c) 2020 by author(s) and Scientific Research Publishing Inc. This work is licensed under the Creative Commons Attribution International License (CC BY 4.0)

http://creativecommons.org/licenses/by/4.0/

\section{Open Access}

\begin{abstract}
Background: There are various health problems in rotating shift workers. There have been few studies on the associations of male climacteric symptoms with duration of working and lifestyle. Objective: The aim of this study was to determine the differences in male climacteric symptoms depending on the number of working years and to determine whether lifestyle habits differ depending on the number of working years in rotating shift workers. Methods: We collected participant's data from the manufacturing companies in Japan during the period from March to May in 2017. We conducted a self-administered questionnaire survey in 1561 male rotating night shift workers. Male climacteric symptoms were evaluated by using the Aging Males' Symptoms (AMS) rating scale. We analyzed 636 rotating shift workers aged over 40 years old whose all AMS data was collected. Results: A significant difference in psychological AMS score was found between men who had worked for $10-19$ years $(9.4 \pm 3.9)$ and men who had worked for more than 40 years $(7.6 \pm 3.0)(p=0.011)$. Sexual functional AMS score significantly differed depending on the number of working years (less than 10 years: $8.1 \pm$ 3.9, 10 - 19 years: $9.8 \pm 4.1,20-29$ years: $7.9 \pm 3.3,30-39$ years: $9.3 \pm 3.5$, more than 40 years: $9.3 \pm 3.5)(\mathrm{p}<0.001)$. The proportion of workers with a balanced meal intake was significantly lower in men who had worked for less than 10 years and the proportions of such workers were significantly higher in men who had worked for $10-19$ years and for more than 40 years. The proportions of men who did not drink alcohol were high in men who had worked for less than 10 years and $20-29$ years and low in men who had
\end{abstract}


worked more than 30 years. Conclusion: Psychological AMS score and sexual functional AMS score are significantly different among the 5 groups according to the number of working years on rotating shift. In addition, well-balanced diet on day shift and reduction of alcohol drinking is a related-factor for long-term rotating night shift workers.

\section{Keywords}

Rotating Night Shift Workers, Male Climacteric Symptoms, Aging Male's Symptoms Rating Scale, Occupational Health, Lifestyle Habit

\section{Introduction}

It is well known that there is disturbance of the circadian rhythm in rotating night shift workers [1] Many studies have shown associations of rotating night shift work with the occurrence of cardiovascular diseases [2], gastrointestinal diseases [3], diabetes mellitus [4] and some cancers [5] [6]. Rotating shift workers also experience disturbance of their social life cycle. It has been reported that levels of euphoria and satisfaction in life were low in shift workers since they cannot spend as much time with their families as day workers can [7]. Therefore, it has been reported that shift work is associated with poor mental health and depression [8]. With regard to male climacteric symptoms, we recently reported that Aging Male's Symptoms (AMS) score in rotating night-shift workers of more than 40 years of age was high and that there were large proportions of men with increased need for sleep and often feeling tired and with decrease in muscular strength. Considering that there are several problems regarding physical and psychological symptoms in rotating night shift workers, it may be difficult for workers to continue with rotating night shift work for a long time. Also, male climacteric symptoms in long-term rotating night shift workers have not been clarified.

With respect to lifestyle habits, it has been reported that a large proportion of rotating shift workers are obese because of insufficient exercise and irregular eating habits and that rotating shift workers are likely to drink alcohol before bedtime [9]. Improvement of lifestyle habits may be important for long-term rotating night shift workers. Also, lifestyle habits of men over the age of 40 years who have worked for a short period and men over the age of 40 years who have worked for a long time may be different. However, lifestyle habits in long-term rotating night shift workers have not been clarified. On the other hand, it has been reported that rotating shift workers in their $50 \mathrm{~s}$ could continue to work for a long time in good health by the support of their family [10]. Kubo et al. reported that support from wives such as preparation of meals and making sure that their husbands maintained their sleeping hours were important for rotating shift workers [10]. Men who have continued rotating shift workers for a long time may have the ability to cope with various symptoms. If they feel male cli- 
macteric symptoms, they may have been able to cope with the symptoms by their lifestyle habits. Therefore, information on lifestyle habits of long-term rotating night shift workers would be useful for rotating night shift workers to continue working in good health.

The aim of this study was to determine the differences in male climacteric symptoms depending on the number of working years and also to determine whether lifestyle habits differ depending on the number of working years in rotating shift workers.

\section{Subjects and Methods}

We asked the managers of general affairs or occupational nurses in 33 companies for cooperation in the study and distributed the questionnaires to 1891 male rotating night shift workers throughout Japan. Male rotating night shift workers who had worked all or some of the hours between $10 \mathrm{pm}$ and $5 \mathrm{am}$ in manufacturing companies were recruited during the period from March to May in 2017. Exclusion criteria were workers under the age of 20 years and fixed night shift workers. We decided the sample size considering the confidence coefficient 95\%, allowance error 5\%, expected response rate $50 \%$ and also the nubmer of participants of each groups according to the number of working years on rotating shift.

The questionnaires were collected from collection boxes or by mail.

A self-administered questionnaire survey was conducted to obtain information about demographic factors (age, body weight, body height, employment status, and presence of social support), working factors (type of shift and period of working) and lifestyle (dietary habits, smoking status, habitual exercise, alcohol consumption and leisure time activity). For dietary habits, we asked about eating breakfast, eating balanced meals during day shifts and eating balanced meals during night shifts. We defined a balanced meal as the intake of a staple food, main dish and side dish. There were multiple answers for the questions about ways of spending free time and consideration of meals before and after night shift. We evaluated male climacteric symptoms by using the AMS questionnaire, which has been used worldwide for assessing male climacteric symptoms [11]. The AMS scale consists of 17 items including 7 somatic symptoms, 5 psychological symptoms and 5 symptoms of sexual dysfunction. The AMS scale is rated with a 5-point Likert-type scale ranging from 1 (none) to 5 (very severe) and the degree of severity of each symptoms are classified as no symptoms, mild, moderate and severe according to total scores [11]. A total score of 26 or less indicates no symptoms, a total score of 27 or more and 36 or less indicates mild symptoms, a total score of 37 or more and 49 or less indicates moderate symptoms, and a total score of 50 or higher indicates severe male climacteric symptoms. Psychological score and sexual dysfunction score of 5 or less indicates no symptoms. A somatic score of 8 or less indicates no symptoms. A psychological score of 6 or more and 8 or less indicates mild symptoms, a psychological score of 9 or more and 12 or less indicates moderate symptoms, and a psychological 
score of 13 or higher indicates severe symptoms. A somatic score of 9 or more and 12 or less indicates mild symptoms, a somatic score of 13 or more and 18 or less indicates moderate symptoms, and a somatic score of 19 or higher indicates severe symptoms. Sexual dysfunction scores of 6 and 7 indicate mild symptoms, a sexual dysfunction score of 8 or more and 10 or less indicates moderate symptoms and a sexual dysfunction score of 11 or higher indicates severe symptoms

Since it has been reported that the number of men with male climacteric symptoms increase after their $40 \mathrm{~s}$ [12], we selected participants whose ages were over 40 years. We divided the participants into 5 groups according to the number of working years ( $<10$ years, $10-19$ years, $20-29$ years, $30-39$ years and $\geq 40$ years).

\subsection{Statistical Analysis}

Background characteristics and lifestyle as dependent variables and number of working years as an independent variable were analyzed by using the chi-square test. Items for which significant differences were found among the 5 groups were also analyzed by residual analysis. When residual values after adjustment were less than or more than $1.96, \mathrm{p}$ values less than 0.05 were considered to be statistically significant, and when residual values after adjustment were less than or more than 2.58 , p values less than 0.01 were considered to be statistically significant. The differences in total AMS scores, somatic sub-scores, psychological sub-scores and sexual sub-scores among the 5 groups were analyzed by the Kruskal-Wallis test. All statistical analyses were conducted using SPSS statistics version 25 for Windows (IBM Corp.).

\subsection{Ethical Consideration}

The Research Ethics Committee of Tokushima University Hospital approved the study (approval number 2745). An explanation sheet and a consent form were sent to the manager of each company, and written informed consent was received after an explanation regarding the study. The subjects were only men who agreed to participate after receiving an explanation of the study from the manager of the company. The explanation sheet included an explanation about the respect for autonomy and anonymization of personal data.

\section{Results}

The overall response rate was $82.5 \%$ (1561/1891). We excluded 26 participants who were under 20 years of age, 11 participants who were fixed night shift workers and 24 participants for whom ages were not known, and we analyzed data for 1500 rotating night shift workers. Of the 1500 participants, we analyzed data for 636 workers aged over 40 years old who responded to all of the questions on 17 male climacteric symptoms. There were 307 participants in their 40 s, 256 in their $50 \mathrm{~s}$ and 73 in their $60 \mathrm{~s}$. Baseline characteristics including age, body mass index (BMI), employment status, living with wives, presence of an 
advisor other than a family member and leisure activities of subjects in the 5 groups according to the number of working years are shown in Table 1. The proportion of regular employees was higher than those of non-regular employee and the proportion of men living with wives were higher than those of without wives in all groups. There was a significant difference in BMI between men who had worked for 20 - 29 years and men in other 4 groups. The proportion of men whose leisure activities were playing television games and using a computer was high in participants who had worked for less than 30 years.

As shown in Table 2, there was a significant difference between total AMS scores in men who had worked for less than 10 years and $(30.9 \pm 12.8)$ men who had worked for $10-19$ years $(34.7 \pm 11.5)(\mathrm{p}=0.025)$. The degree of physical symptoms was moderate in all groups, and there was no significant difference among all groups. Physical AMS scores tended to be different in the 5 groups. There was a significant difference between psychological AMS scores in men who had worked for $10-19$ years $(9.4 \pm 3.9)$ and men who had worked for more

Table 1. Background characteristics according to number of working years.

\begin{tabular}{|c|c|c|c|c|c|c|c|}
\hline Number of working years & Years & $<10$ & $10-19$ & $20-29$ & $30-39$ & $\geq 40$ & $P$ value \\
\hline \multirow[t]{2}{*}{ Number } & & 97 & 88 & 212 & 142 & 97 & \\
\hline & $40 \mathrm{~s}$ & $68(70.1)$ & $50(56.8)$ & $175(82.5)$ & $14(9.9)$ & 0 & \\
\hline Age & $50 \mathrm{~s}$ & $22(22.7)$ & $34(38.6)$ & $35(16.5)$ & $115(81.0)$ & $50(51.5)$ & $<0.001$ \\
\hline \multirow{4}{*}{ BMI } & Mean \pm SD & $24.1 \pm 3.5$ & $24.1 \pm 3.7$ & $24.0 \pm 3.2$ & $23.9 \pm 3.3$ & $24.3 \pm 3.5$ & 0.396 \\
\hline & $>25$ & $65(67.0)$ & $55(62.5)$ & $161(75.9)$ & $95(66.9)$ & $56(57.7)$ & \multirow{3}{*}{0.047} \\
\hline & $\leq 25$ & $30(30.9)$ & $32(36.4)$ & $50(23.6)$ & $46(32.4)$ & $36(37.1)$ & \\
\hline & Missing & $2(2.1)$ & $1(1.1)$ & $1(0.5)$ & $1(0.7)$ & $5(5.2)$ & \\
\hline \multirow[t]{2}{*}{ Employment status } & Non-regular employee & $38(39.2)$ & $24(27.3)$ & $9(4.2)$ & $7(4.9)$ & $33(34.0)$ & \multirow[t]{2}{*}{$<0.001$} \\
\hline & Missing & $3(3.1)$ & 0 & 0 & 0 & $1(1.0)$ & \\
\hline \multirow{2}{*}{ Living with wife } & Yes & $62(63.9)$ & $60(68.2)$ & $166(78.3)$ & $128(88.3)$ & $86(87.6)$ & \multirow{2}{*}{$<0.001$} \\
\hline & No & $35(36.1)$ & $28(31.8)$ & $46(21.7)$ & $14(9.9)$ & $11(11.3)$ & \\
\hline \multirow{3}{*}{$\begin{array}{c}\text { Presence of an advisor } \\
\text { other than a family } \\
\text { member }\end{array}$} & Yes & $48(49.5)$ & $50(56.8)$ & $126(59.4)$ & $67(47.2)$ & $39(40.2)$ & \multirow{3}{*}{0.025} \\
\hline & No & $49(50.5)$ & $38(43.2)$ & $85(40.1)$ & $73(51.4)$ & $55(56.7)$ & \\
\hline & Missing & 0 & 0 & $1(0.5)$ & $2(1.4)$ & $3(3.1)$ & \\
\hline \multirow{4}{*}{$\begin{array}{c}\text { Leisure activities } \\
\text { (multiple answers allowed) }\end{array}$} & Shopping & $41(42.3)$ & $36(40.9)$ & $93(43.9)$ & $64(45.1)$ & $31(32.0)$ & \\
\hline & Playing TV games\& using computer & $32(33.0)$ & $28(31.8)$ & $69(32.5)$ & $25(17.6)$ & $12(12.4)$ & \\
\hline & Exercising & $23(23.7)$ & $28(31.8)$ & $59(27.8)$ & $31(21.8)$ & $25(25.8)$ & \\
\hline & $\begin{array}{l}\text { Playing pinball games and bicycle } \\
\text { races }\end{array}$ & $19(19.6)$ & $28(31.8)$ & $49(23.1)$ & $37(26.1)$ & $25(25.8)$ & \\
\hline
\end{tabular}

Numbers in parentheses are percentages. 
Table 2. Aging male symptoms score according to number of working years.

\begin{tabular}{|c|c|c|c|c|c|c|c|}
\hline $\begin{array}{c}\text { Number of } \\
\text { working years }\end{array}$ & & $<10$ & $10-19$ & $20-29$ & $30-39$ & $\geq 40$ & $P$ value \\
\hline Number & & 97 & 88 & 212 & 142 & 97 & \\
\hline \multirow{2}{*}{$\begin{array}{l}\text { AMS total } \\
\text { scores }\end{array}$} & $\begin{array}{c}\text { Median } \\
(25 \%-75 \% \text { tile })\end{array}$ & $\begin{array}{c}26.7 \\
(22-38)\end{array}$ & $\begin{array}{c}32.8 \\
(25-43.5)\end{array}$ & $\begin{array}{c}28.8 \\
(23-38)\end{array}$ & $\begin{array}{c}29.1 \\
(24-39)\end{array}$ & $\begin{array}{c}28.4 \\
(23-35)\end{array}$ & \multirow{2}{*}{$\begin{array}{c}0.033 \\
<10 \text { vs } 10-19(\mathrm{p}=0.025)\end{array}$} \\
\hline & Mean \pm SD & $30.9 \pm 12.8$ & $34.7 \pm 11.5$ & $31.4 \pm 11.0$ & $31.9 \pm 10.3$ & $30.4 \pm 9.5$ & \\
\hline \multirow{2}{*}{$\begin{array}{l}\text { Somatic } \\
\text { sub-scores }\end{array}$} & $\begin{array}{c}\text { Median } \\
(25 \%-75 \% \text { tile })\end{array}$ & $\begin{array}{c}12.8 \\
(10-18)\end{array}$ & $\begin{array}{c}15.3 \\
(12-19.5)\end{array}$ & $\begin{array}{c}14.0 \\
(11-18)\end{array}$ & $\begin{array}{c}13.7 \\
(11-18)\end{array}$ & $\begin{array}{c}13.1 \\
(11-16)\end{array}$ & \multirow[t]{2}{*}{0.054} \\
\hline & Mean \pm SD & $14.2 \pm 5.8$ & $15.6 \pm 4.9$ & $14.7 \pm 5.3$ & $14.4 \pm 4.8$ & $13.6 \pm 4.3$ & \\
\hline \multirow{2}{*}{$\begin{array}{l}\text { Psychological } \\
\text { sub-scores }\end{array}$} & $\begin{array}{c}\text { Median } \\
(25 \%-75 \% \text { tile })\end{array}$ & $\begin{array}{c}6.9 \\
(5-10)\end{array}$ & $\begin{array}{c}8.6 \\
(6-12)\end{array}$ & $\begin{array}{c}7.5 \\
(5.5-11)\end{array}$ & $\begin{array}{c}7.2 \\
(5-10)\end{array}$ & $\begin{array}{c}6.7 \\
(5-9)\end{array}$ & \multirow{2}{*}{$\begin{array}{c}0.013 \\
10-19 \text { vs } \geq 40(\mathrm{p}=0.011)\end{array}$} \\
\hline & Mean \pm SD & $8.6 \pm 4.4$ & $9.4 \pm 3.9$ & $8.8 \pm 4.0$ & $8.2 \pm 3.4$ & $7.6 \pm 3.0$ & \\
\hline \multirow{2}{*}{$\begin{array}{c}\text { Sexual } \\
\text { sub-scores }\end{array}$} & $\begin{array}{c}\text { Median } \\
(25 \%-75 \% \text { tile })\end{array}$ & $\begin{array}{c}6.8 \\
(5-10)\end{array}$ & $\begin{array}{c}9.1 \\
(6-13)\end{array}$ & $\begin{array}{c}6.8 \\
(5-10)\end{array}$ & $\begin{array}{c}8.8 \\
(6-11)\end{array}$ & $\begin{array}{c}8.8 \\
(7-11)\end{array}$ & $\begin{array}{c}<0.001 \\
20-29 \text { vs } 10-19(\mathrm{p}=0.001) \text { or } \\
30-39(\mathrm{p}<0.001) \text { or } \geq 40(\mathrm{p}=0.002)\end{array}$ \\
\hline & Mean \pm SD & $8.1 \pm 3.9$ & $9.8 \pm 4.1$ & $7.9 \pm 3.3$ & $9.3 \pm 3.5$ & $9.3 \pm 3.5$ & $\begin{array}{c}<10 \text { vs } 10-19(\mathrm{p}=0.010) \text { or } \\
30-39(\mathrm{p}=0.011) \text { or } \geq 40(\mathrm{p}=0.026)\end{array}$ \\
\hline
\end{tabular}

SD: standard deviation.

than 40 years $(7.6 \pm 3.0)(\mathrm{p}=0.011)$. Sexual functional AMS score in men who had worked for $20-29$ years $(7.9 \pm 3.3)$ was significantly different from the scores in men who had worked for 10 - 19 years $(9.8 \pm 4.1)(\mathrm{p}=0.001)$, for 30 39 years $(9.3 \pm 3.5)(\mathrm{p}<0.001)$ and for more than 40 years $(9.3 \pm 3.5)(\mathrm{p}=$ 0.002). Sexual functional AMS score in men who had worked for less than 10 years $(8.1 \pm 3.9)$ was also significantly different from the scores in men who had worked for $10-19$ years $(9.8 \pm 4.1)(\mathrm{p}=0.010)$, for $30-39$ years $(9.3 \pm 3.5)(\mathrm{p}=$ $0.011)$ and for more than 40 years $(9.3 \pm 3.5)(\mathrm{p}=0.026)$.

As can be seen in Table 3, the proportions of men who had breakfast were higher than the proportions of men who did not have breakfast in all 5 groups, and there was no significant difference in the proportions of men who had breakfast in the 5 working period groups. There was a significant association between the proportion of shift workers with a high frequency of balanced meals during day shifts and number of working years $(\mathrm{p}<0.001)$. After residual analysis, the proportion of such men was significantly lower in men who had worked for less than 10 years and the proportions were significantly higher in men who had worked for 10 - 19 years and for more than 40 years. There was no significant association of the proportion of shift workers who had balanced meals during night shifts with the number of working years. The proportion of men who do not pay attention to eating habits before and after night shift work was $57.7 \%$. Regarding the eating habits that they paid attention before and after night shift work, $18.7 \%$ of the men tried not to overeat, $14.3 \%$ tried to eat many vegetables and $9.6 \%$ gave consideration to calories.

The proportions of men with a current smoking habit were not significantly 
Table 3. Lifestyle according to number of working years.

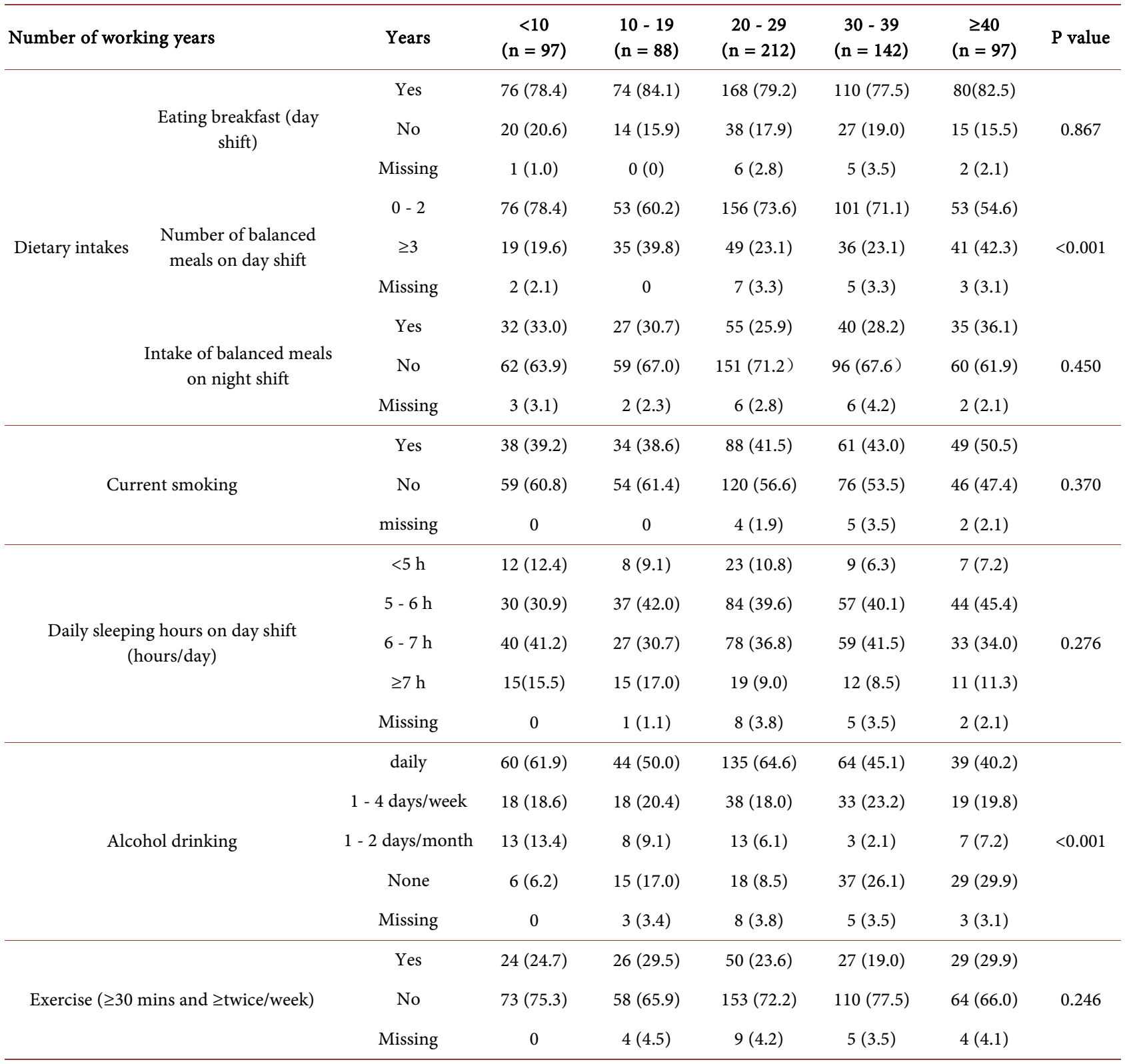

Numbers in parentheses are percentages.

different in the 5 groups, but the proportion increased with increase in the number of working years more than 20 years. The proportions of men whose daily sleeping hours were $6-7$ hours were high in men who had worked for less than 10 years and for 30 - 39 years. There was no significant difference in sleeping hours in the 5 groups. The proportion of men who drank alcohol every day was significantly high in men who had worked for 20 - 29 years and significantly decreased with increase in the number of working years. The proportions of men who did not drink alcohol were low in men who had worked for less than 10 years and $20-29$ years and high in men who had worked for $30-39$ years and more than 40 years. There was not a significant difference in the propor- 
tions of men who did regular exercise in the 5 groups.

\section{Discussion}

In the present study, we found that there were significant differences in total AMS score among the 5 groups, especially psychological symptoms and sexual functional symptoms. Long-term shift workers did not tend to have a high AMS score. In addition, rotating night shift workers who had worked for over 40 years tended to pay attention to dietary balance during day shifts. The proportion of men who drank alcohol every day significantly decreased with increase in the number of working years.

Although it was assumed that the total AMS score in shift workers would increase with an increase in the number of working years, we found that the score was highest in men who had worked for 10 - 19 years. One possible reason is the age distribution in men who had worked for $10-19$ years. The mean age of men who had worked for $10-19$ years was 49.4 years, while the mean age of men who had worked for 20 - 29 years was 46.4 years. The proportion of non-regular employees in men who had worked for 10 - 19 years was $27.3 \%$, and the proportion was higher than the proportions in men who had worked for 20 - 29 years (4.2\%) and for 30 - 39 years (4.9\%). Therefore, financial instability may be involved in the high AMS score. Also, men who had worked for 10 - 19 years might have become used to work and might be busy due to an increased workload in a responsible position.

There was no significant difference in somatic AMS score among the 5 groups. Since shift workers who had worked for a long time did not have a high somatic AMS score, long-term shift workers might be able to successfully cope with somatic symptoms. They might visit hospitals and consult a doctor when they feel physical symptoms. Psychological AMS score was significantly lower in men who had worked for more than 40 years. Long-term shift workers might be supported by their families. Low sexual functional AMS scores in shift workers who had worked for less than 10 years and for $20-29$ years may be due to the high proportion of men in their $40 \mathrm{~s}$. However, there was no significant difference between sexual functional AMS scores for men who had worked for 10 - 19 years, for 30 - 39 years and for more than 40 years despite the difference in age distribution in these groups. An increase in the proportion of men with sexual functional symptoms was not found in long-term shift workers. Shift workers who have worked for more than 30 years might be able to appropriately manage their lifestyle including dietary habits.

It was shown in a previous study that long-term shift workers paid attention to lifestyle habits, particularly dietary habits [10]. In all of the 5 groups in the present study, the proportion of workers who had breakfast when working day shift was higher than the proportion of workers who did not have breakfast when working day shift. The proportion of men who had breakfast during day shifts was high in workers who had worked for more than 40 years, suggesting 
that they placed importance on having breakfast. According to the "The National Health and Nutrition Examination Survey in 2018", the proportions of Japanese men who take staple food, main dish and side dish everyday were $39.4 \%$ in their $40 \mathrm{~s}, 42.3 \%$ in their $50 \mathrm{~s}$ and $49.2 \%$ in their $60 \mathrm{~s}$ [13]. Shift workers also who had worked for 10 - 19 years and for more than 40 years paid attention to a balanced diet during day shifts. However, a significant difference in the proportion of men who had a balanced diet during night shifts was not found among the 5 groups. Also, rotating shift workers did not tend to pay attention to meals before and after night shift. Although we predicted that rotating night shift workers would have a high level of awareness of dietary habits, the results obtained from the present study were different. The wives of night shift workers may support their dietary habits during day shifts.

It has been reported that shift workers consume alcohol to help them sleep [9]. However, it was suggested for men who worked for more than 30 years on rotating shift refrain from drinking alcohol for their health. In the present study, shift workers who have worked for more than 30 years may avoid excessive alcohol drinking in order to take care of their health and continue with shift work.

The National Health and Nutrition Examination Survey in 2018 showed that the proportions of Japanese men who smoked were $37 \%$ in their $40 \mathrm{~s}, 35.2 \%$ in their $50 \mathrm{~s}$ and $30.9 \%$ in their $60 \mathrm{~s}$ [13]. In the present study, the proportion of men with a current smoking habit among men who had worked for over 40 years was especially high (50.5\%), although there was no significant difference in the proportions of current smokers among the 5 groups. Rotating night shift workers should already understand that smoking is harmful to their health, but they may smoke for relief of stress from work. Bushnel et al. reported that the smoking rate in shift workers was 1.38-times higher than that in day workers [14] and suggested that lack of sleep and fatigue due to working at night leads to smoking by workers to maintain alertness. Fujino et al. also reported that the smoking rate in shift workers was 2.5-times higher than that in day shift workers and that the risk of death due to cardiovascular diseases in shift workers was 2.32-times higher than that in day workers based on the results of a longitudinal study during the period from 1988 to 1990 . Thus, they suggested that a smoking habit is a risk factor for death [15]. On the other hand, the Korean National Health and Nutrition Examination Survey in 2017 showed that there was no significant difference in smoking rate between day workers (43.5\%) and rotating shift workers (46.3\%) [16]. The reason for the difference in the results is unknown. Considering the high proportion of shift workers who smoke, it is important for occupational health nurses to provide information regarding health issues of smoking.

It was shown that the proportions of workers who did not exercise among shift workers who worked for 8 hours, 10 hours and 12 hours a day were 1.18-times, 1.25-times and 1.33-times higher than the proportion in day workers who worked for 8 hours a day in a survey of 18,163 men and 8279 women aged 
18 - 74 years [14]. In the present study, we found that the proportion of men who continue to do regular exercise in rotating shift workers for more than 40 years was as high as that for $10-19$ years. Although it has been assumed that the proportion of men who do regular exercise decreases with advance of age, rotating shift workers who had worked for more than 40 years may have continued to do exercise because their exercise habit had become established or because they felt that they need to exercise. Atkinson et al. suggested that shift workers can use fitness and health clubs during a time of day when most people do not use such facilities [17]. Kim et al. reported that the proportion of shift workers in Korea who exercised in their spare time was 1.58 - 1.72-times higher than the proportion of day workers who exercised, suggesting that rotating shift workers can manage their spare time well [18].

In a longitudinal study conducted over a period of 14 years, Tanaka et al. reported that the periods of working in rotating shift workers in their $40 \mathrm{~s}$ whose body weights had increased by $5 \%$ and $10 \%$ were 6.8 years and 8.8 years, respectively, and that the periods of working in rotating shift workers in their $50 \mathrm{~s}$ whose body weights had increased by $5 \%$ and $10 \%$ were 4.0 years and 4.5 years, respectively. Thus, it was suggested that long-term rotating shift workers are likely to be obese [19]. In the present study, there was a significant difference in BMI between men who had worked for 20 - 29 years and men in other 4 groups. We could not assess rates of increases in body weights since we did not ask about body weights at the time point when the workers first started shift work.

This study had a large sample size. To the best of our knowledge, there has been no study with such a large sample size for shift workers. However, this study has several limitations. First, this study was a cross-sectional study. A prospective study on the causal relationship between the number of working years and AMS score is needed. Second, it is difficult to distinguish from male climacteric symptoms since mild depression and anxiety disorder cause similar psychological symptoms. Third background factors for the number of working years including the age when starting shift work may be different. Moreover, differences in age distribution and employment status among the groups might affect the results of the AMS scores. Finally, we did not have questions regarding the willingness to continue shift work and satisfaction with shift work. It has been reported that shift workers responded that they want to quit shift work with consideration of their health but that they are continuing shift work for financial reasons [10]. In general, rotating night shift workers whose health has deteriorated change to a day shift position, which is the so-called healthy worker's effect. However, we could not follow up men who transferred to day shift work. It has been shown that shift workers account for $16.4 \%$ of the USA workforce [20]. Night shift workers are necessary for human resources. Further research is needed for long-term night shift workers.

In conclusion, psychological AMS score and sexual functional AMS score are significantly different among the 5 groups according to the number of working 
years on rotating shift. Also, a well-balanced diet on day shift and reduction of alcohol drinking is a related-factor for long-term rotating night shift workers.

\section{Funding}

This research did not receive any specific grant from funding agencies in the public, commercial, or not-for-profit sectors.

\section{Acknowledgements}

The authors would like to show their appreciation to participants, managers of general affairs and occupational nurses. We are also grateful for assistance given by Professor Iwamoto.

\section{Conflicts of Interest}

The authors declare no conflicts of interest regarding the publication of this paper.

\section{References}

[1] Boivin, D.B., Duffy, J.F., Kronauer, R.E. and Czeisler, C.A. (1996) Dose-Response Relationships for Resetting of Human Circadian Clock by Light. Nature, 379, 540-542. https://doi.org/10.1038/379540a0

[2] Karlsson, B., Alfredsson, L., Knutsson, A., Andersson, E. and Torén, K. (2005) Total Mortality and Cause-Specific Mortality of Swedish Shift and Day Workers in the Pulp and Paper Industry in 1952-2001. Scandinavian Journal of Work, Environment \& Health, 31, 30-35. https://doi.org/10.5271/sjweh.845

[3] Pietroiusti, A., Forlini, A., Magrini, A., Galante, A., Coppeta, L., Gemma, G. and Romeo, E. (2006) Shift Work Increases the Frequency of Duodenal Ulcer in H Pylori Infected Workers. Occupational and Environmental Medicine, 63, 773-775. https://doi.org/10.1136/oem.2006.027367

[4] Kecklund, G. and Axelsson, J. (2016) Health Consequences of Shift Work and Insufficient Sleep. British Medical Journal, 355, i5210. https://doi.org/10.1136/bmj.i5210

[5] Gapstur, S.M., Diver, W.R., Stevens, V.L., Carter, B.D., Teras, L.R. and Jacobs, E.J. (2014) Work Schedule, Sleep Duration, Insomnia, and Risk of Fatal Prostate Cancer. American Journal of Preventive Medicine, 46, S26-S33. https://doi.org/10.1016/j.amepre.2013.10.033

[6] Kubo, T., Ozasa, K., Mikami, K., Wakai, K., Fujino, Y., Watanabe, Y., Miki, T., Nakao, M., Hahasyhi, K., Suzuki, K., Mori, M., Washio, M., Sakauchi, F., Ito, Y., Yoshimura, T. and Tamakoshi, A. (2006) Prospective Cohort Study of the Risk of Prostate Cancer among Rotating-Shift Workers: Findings from the Japan Collaborative Cohort Study. American Journal of Epidemiology, 64, 549-555. https://doi.org/10.1093/aje/kwj232

[7] Kaliterna, L.J., Prizmic, L.Z. and Zganec, N. (2004) Quality of Life, Life Satisfaction and Happiness in Shift and Non-Shiftworkers. Revista de Saúde Pública, 38, 3-10. https://doi.org/10.1590/S0034-89102004000700002

[8] Kaneko, S., Maeda, T., Sasaki, A., Sato, A., Tanaka, K., Kobayashi, T. and Fukushima, T. (2004) Effect of Shift Work on Mental State of Factory Workers. Fukushima Journal of Medical Science, 50, 1-9.

[9] Dorrian, J., Heath, G., Sargen, C., Banks, S. and Coates, A. (2017) Alcohol Use in 
Shiftworkers. Accident Analysis \& Prevention, 99, 395-400. https://doi.org/10.1016/j.aap.2015.11.011

[10] Kubo, S. and Tada, T. (2014) Work life Difficulties and Coping Strategies of Male Night-Shiftworkers. Journal of Shikoku Public Health Society, 59, 93-102.

[11] Heinemann, J., Zimmermann, T., Vermeulen, A., Tiel, C. and Hummel, W. (1999) A New Aging Males' Symptoms' (AMS) Rating Scale. Aging Male, 2, 105-114. https://doi.org/10.3109/13685539909003173

[12] Wu, F.C., Tajar, A., Beynon, J.M., Pye, S.R., Silman, A.J, Finn, J.D., O’Neill, T.W., Bartfai, G., Casanueva, F.F., Forti, G., Giwercman, A., Han, T.S., Kula, K., Lean, M.E.J., Pendleton, N., Punab, M., Boone, S., Vanderschueren, D., Labrie, F. and Huhtaiemi, L.T. (2010) Identification of Late-Onset Hypogonadism in Middle-Aged and Elderly Men. The New England Journal of Medicine, 363, 123-135. https://doi.org/10.1056/NEJMoa0911101

[13] Ministry of Health, Labour and Welfare. The National Health and Nutrition Survey in Japan, 2018. https://www.mhlw.go.jp/content/000615345.pdf

[14] Bushnell, P.T., Colombi, A., Caruso, C.C. and Tak, S. (2010) Work Schedules and Health Behavior Outcomes at a Large Manufacturer. Indsutrial Health, 48, 395-405.

[15] Fujino, Y., Iso, H., Tamakoshi, A., Inaba, Y., Koizumi, A., Kubo, T. and Yoshimura, T. (2006) A Prospective Cohort Study of Shift Work and Risk of Ischemic Heart Disease in Japanese Male Workers. American Journal of Epidemiology, 164, 128-135. https://doi.org/10.1093/aje/kwj185

[16] Bae, J.M., Song, Y.M., Shin, J.Y., Choi, B.Y., Keum, J.H. and Lee, E.A. (2017) The Association between Shift Work and Health Behavior: Findings from the Korean National Health and Nutrition Examination Survey. Korean Journal of Family Medicine, 38, 86-92. https://doi.org/10.4082/kjfm.2017.38.2.86

[17] Atkinson, G., Fullick, S., Grindey, C. and Maclaren, D. (2008) Exercise, Energy Balance and the Shift Worker. Sports Medicine, 38, 671-685. https://doi.org/10.2165/00007256-200838080-00005

[18] Kim, C. and Cho, Y. (2015) Working Conditions and Leisure-Time Physical Activity among Waged Workers in South Korea: A Cross-Sectional Study. Journal of Occupational Health, 57, 259-267. https://doi.org/10.1539/joh.14-0028-OA

[19] Tanaka, K., Sakata, K., Oishi, M., Morimoto, H., Nakada, S., Uetani, M., Nogawa, K. and Suwazono, Y. (2010) Estimation of the Benchmark Duraion of Shiftwork Associated with Weight Gain in Male Japanese Workers. Chronobiology International, 27, 1895-1910. https://doi.org/10.3109/07420528.2010.516045

[20] U.S. Bureau of Labour Satistics, Workers by Shift Usually Worked and Selected Characteristics. Averages for the Period, 2017-2018.

https://www.usa.gov/federal-agencies/bureau-of-labor-statistics 